Folia Histórica del Nordeste, $\mathbf{N}^{\mathbf{0}} 21$ (Resistencia, 2013) IIGHI, IH - CONICET, UNNE

\title{
FIESTA Y NACIÓN EN PARAGUAY. LAS CELEBRACIONES DE LA INDEPENDENCIA DURANTE EL SIGLO XIX
}

\author{
Feast and Nation in Paraguay. The celebrations of the Independence during \\ the 19th century
}

Herib Caballero Campos

\section{Resumen}

La presente investigación tuvo por principal propósito responder a ¿cómo se celebró la Independencia del Paraguay a lo largo del siglo XIX?, una temática escasamente desarrollada en la historiografía Paraguaya. Así mismo se indagó sobre el vínculo de las mencionadas celebraciones con la concepción de Nación. Para lo cual se ha utilizado la metodología histórica y el análisis de fuentes primarias y secundarias desde la perspectiva de la Historia de las Mentalidades, a partir de un adecuado marco teórico. Para desarrollar el análisis histórico de las celebraciones se ha recurrido principalmente a las noticias publicadas en los periódicos en aquellos años que aleatoriamente fueron seleccionados para establecer una tendencia por períodos históricos. Su principal aporte fue el de develar cómo cambiaron los festejos de la Independencia y cómo los mismos se realizaron en el marco de un entramado complejo originado en las tensiones propias entre la élite gobernante y el pueblo en general.

$$
<\text { Paraguay }><\text { Fiesta }><\text { Nación }><\text { Independencia }>
$$

\begin{abstract}
This research intended to answer the question on how was the Independence of Paraguay celebrated throughout the 19th century. This is a topic scarcely developed in the Paraguayan historiography. Likewise, it analyzed the links between those celebrations and the concept of Nation. The historical methodology was applied and the analysis of primary and secondary sources was done from the perspective of the History of the Mentalities. The study of these celebrations was mainly based upon newspapers which were randomly selected to establish trends by historical periods. Its main contribution was to reveal that the feasts of the Independence changed over time and that they were performed within a complex matrix which unfolded tensions between the ruling elite and the people.
\end{abstract}

$$
<\text { Paraguay }><\text { Feast }><\text { Nation }><\text { Independence }>
$$




\section{Introducción}

Está investigación surge a partir de lo que implicó la vivencia de las celebraciones del Bicentenario de la Independencia del Paraguay, lo que nos llevó a pensar de qué forma las fiestas conmemorativas de la independencia a lo largo del siglo XIX permitieron a los habitantes del Paraguay construir la identidad con la nación. En esa línea creemos que el trabajo de Juan Carlos Garavaglia es esclarecedor cuando afirma que dicha línea de investigación permite “...recuperar una parte de los contenidos simbólicos más ricos que la fiesta vehiculizaba en el antiguo régimen hispano; por otra parte, este camino resulta también útil para mostrar algunos cambios que los acontecimientos que se desarrollan desde 1810 en adelante impondrían a los regocijos populares" (Garavaglia, 2007:57).

El vínculo entre la fiesta y la construcción de la nación ha sido estudiado por varios autores en diversos países y desde diferentes perspectivas. Pues es indudable que la fiesta tiene un claro objetivo desarrollar la construcción colectiva de la nación (Garavaglia, 2002), o expresar la cultura cívica del Estado (Pérez-Rayón, 1993) o permitir que los habitantes expresen su lealtad al estado y a la monarquía en el Brasil durante la regencia (Campos Basile, 2006). Mientras que en Costa Rica la utilización del ceremonial festivo y la liturgia cívica como herramienta para la consolidación de una nueva legitimidad política (Díaz Arias, 2007) así como la utilización de los festejos en la construcción del imaginario de la nación y la república en el medio de rupturas y continuidades (Ortemberg, 2004).

En Paraguay la fiesta y las celebraciones han sido estudiadas en diversas etapas y facetas como por ejemplo para la época colonial se pueden mencionar el artículo de Blas Garay sobre el paseo del Estandarte Real y el de Liliana Brezzo sobre la fiesta organizada con motivo de la concesión al Príncipe de la Paz del cargo de Regidor Perpetuo del Cabildo de Asunción (Brezzo, 2002). Para el período republicano Alberto Moby Ribeiro Da Silva, estudio los bailes y fiestas populares, que según el autor se entroncan con una tradición instaurada desde el estado (Ribeiro Silva, 2010) y los más vinculados con esta línea de trabajo como el excelente análisis de los festejos del Centenario (Gómez Florentín, Chesterton, 2012), y el que estudia los festejos de la independencia a comienzos del siglo XX (González, 2012).

Este artículo parte del principio que "la tradición inventada implica un grupo de prácticas normalmente gobernadas por reglas aceptadas abierta o tácitamente y de naturaleza simbólica o ritual, que buscan inculcar determinados valores o normas de comportamiento por medio de su repetición, lo cual implica automáticamente continuidad con el pasado" (Hobsbawm \& Ranger 2002:8), pues ante todo debemos entender que la Fiesta "ha persistido en ser un artefacto de expresión y acción sociales, un dispositivo donde vemos desplegarse modelos de acción colectiva y la dramatización de las emociones y sentimientos que alimentan la vida social" (Pujol Cruells, 2006). 
Por lo que pretendemos demostrar que las Fiestas de la Independencia en el Paraguay durante el siglo XIX fueron transformándose de acuerdo a los objetivos y la ideología de la élite gobernante.

Para analizar la evolución de las fiestas estableceremos períodos en los cuales los festejos mantienen un denominador común, de tal forma que facilite la comprensión de los cambios que se sucedieron en los festejos conmemorativos de la Independencia durante el siglo XIX. Las etapas son las siguientes: a) la etapa inicial (1812-1842), b) la etapa de la consolidación (1842-1870) y la c) la etapa liberal (1870-1900).

\section{a) La Etapa Inicial (1812-1842). Del Primer Aniversario a la Ratificación de la Independencia}

En esta etapa se observa cómo las primeras celebraciones mantienen todo el ritual de las celebraciones del antiguo régimen. El proceso independentista paraguayo se inició el 14 de mayo de 1811 cuando las tropas del cuartel comandadas por el capitán Pedro Juan Caballero obligaron al gobernador español Bernardo de Velasco para que aceptase dos vocales en el cogobierno. Del 17 al 21 de junio se reunió una junta general que designó a una junta superior gubernativa integrada por cinco miembros y presidida por el brigadier Fulgencio Yegros.

En 1812 para celebrar el primer aniversario de la gesta independentista, los miembros presentes en la Junta Superior Gubernativa, el brigadier Fulgencio Yegros, Fernando de la Mora y el capitán Pedro Juan Caballero a través de un auto remitido a los alcaldes de primer y segundo voto de la ciudad de Asunción, declararon que “... el 15 es día de Gala y Besamanos y que debe haber Misa y Te Deum en la Santa Iglesia Catedral, e iluminar la noche del 14 esas Casas Consistoriales y a fin de hacer más plausible la gloriosa conmemoración de dicho día, mandarán poner cada uno de Vuestras Mercedes un preso en libertad cuyo delito no sea tan grave...." (ANA, SH, 218-1). El hecho de liberar los presos en días de festividad es una tradición de las fiestas coloniales (Garavaglia; 2007). Según Granze fueron cuatro los delincuentes liberados por los alcaldes de Asunción (Viola, 2003).

Según el Diario de los Sucesos Memorables, cuya autoría es atribuida a Juan Manuel Granze los festejos en el año 1812 empezaron en la mañana del 14 de mayo, de la siguiente forma:

“A las 9 de la mañana se anunció al público en bando solemne con música militar nueva, que en este acto se estrenó, la función del día siguiente en memoria de la revolución del 14 de mayo ppdo, se mandó asistiese todo el vecindario á la misa, Tedeum y besamano con iluminación de calles so pena de 4 pesos de multa [...] Después de las oraciones hubo salva de artillería, se enarboló el pabellón tricolor, hubo música en la plaza, se iluminaron las calles y en cada media hora se 
disparó un cañonazo en la plaza, toda la noche hasta el sol del día 15" (Viola, 2003:177).

Al día siguiente el día 15 de mayo el propio obispo fray Pedro García Panés dio la pontifical, y el doctor Viana fue el encargado de la homilía solemne. Posteriormente las tropas hicieron el voto y juramento en honor de San Isidro, quien fue elegido como patrón del ejército. El pueblo acudió a la Catedral para asistir al Tedeum, a la noche se realizó un baile con la asistencia de los miembros de la Junta Gubernativa y miembros de la sociedad (Viola, 2003).

Los festejos con motivo del primer aniversario de la Revolución, continuaron hasta el 20 de junio de 1812, pues los miembros de la Junta Superior Gubernativa dispusieron que también sea día de estampa, gala y besamanos “... lo sea el día 20 de junio en que se hade [sic] celebrar la memoria de la instalación de esta Junta..." (ANA, SH, 218-1).

Dichas conmemoraciones fueron bastante prolongadas y ofrecieron una variedad de celebraciones a los habitantes de la ciudad de Asunción, según el testimonio el Diario de los Sucesos Memorables, en el cual consta que el jueves 21 de mayo:

"A las nueve de la mañana se promulgó bando muy solemne, con música, etc. En que se manda que para el 19 y 20 del mes venidero se prepare todo vecino estante y habitante de esta capital con caballos y jaeses á proporción de sus facultades, so pena de ser tenido por infidente y sospechoso para acompañar al Real Estandarte del señor desdichado don Fernando VII y se convoca por lo mismo á los corregidores de todos los pueblos de Misiones y Provincia, y con justicia y regidor de cada villa..." (Viola, 2003:179,180).

Los festejos se iniciaron el 19 de junio con un llamativo hecho, por un bando se emplazó a los desafectos al gobierno para que abandonen la provincia en un plazo de 15 días, luego se enarboló el Real Estandarte con cintas tricolores; de la actividad participaron cerca de 60 jinetes que se dirigieron hasta Samuhú Pere ${ }^{1}$, en las afueras de la ciudad. Dicho lugar estaba adornado con:

“...geroglificos [sic], de árbol de la libertad y demostraciones que se hicieron de regocijo en su contorno por los vocales" (Viola, 2003:183). Acabado el paseo del Real Estandarte por la tarde, las actividades continuaron por la noche con un baile en el cabildo de la ciudad, además menciona el diario que hubo “... orquesta de música por las calles, iluminación en todas las casas y arcos triunfales que se erigieron en las bocas calles á costa del gremio de artesanos..." (Viola, 2003: 183).

\footnotetext{
${ }^{1}$ Hoy sería en las cercanías de la Avenida España y la calle Brasil de la ciudad de Asunción.
} 
Al día siguiente, 20 de junio de 1812, las celebraciones se iniciaron con el paseo del Real Estandarte hasta Santo Domingo, luego hubo una celebración en la catedral con presencia del obispo y prédica del doctor Rivera, quien se refirió a:
“... $1^{\circ}$ las obligaciones del gobierno para con Dios, la religión y la patria; $2^{\circ}$ las del pueblo para con el gobierno y al concluir dijo un discurso irritante contra los votos de algunos individuos de las cortes, sobre los artículos de igualdad entre europeos y americanos". Tras el incidente en el cual se evidenció la adicción al antiguo régimen por parte de varios miembros de la sociedad y principalmente del clero, los festejos prosiguieron con la representación de una comedia teatral Más vale tarde que nunca" (Viola, 2003: 183).

El 21 de junio se realizó un juego de sortijas, el lunes 22 hubo un baile al cual asistieron los miembros del gobierno, al día siguiente martes se repitieron nuevamente los juegos de sortija y por la noche se representó nuevamente la comedia, finalizaron los festejos el miércoles 24 con el baile organizado por el comerciante inglés John Parish Robertson en su lugar de residencia ubicada en las afueras de la ciudad (Viola, 2003, 183-184).

Sobre el segundo aniversario de la Revolución de Independencia, no hemos encontrado ningún documento oficial al respecto de conmemorar dicha fecha, y en el Diario de Sucesos Memorables, su autor anotó cuanto sigue "No hubo otra demostración en aniversario de la revolución del cuartel que la función de iglesia solemne predicó el Dr. D. Hipólito Quintana" (Viola, 2003: 207).

En ese mismo año como respuesta a la propuesta de unidad formulada por el gobierno de Buenos Aires, el Congreso General reunido en el templo de la Merced entre el 30 de septiembre y el 12 de octubre, resolvió crear la República, y se estableció como forma de gobierno el Consulado ejercido por Fulgencio Yegros y José Gaspar Rodríguez de Francia, con lo cual se produce el fin de la etapa autonomista y se cerraba toda posibilidad de unidad con las demás provincias que componían el virreinato del Río de la Plata.

En 1814 el Congreso General dispuso el fin del gobierno consular y estableció el gobierno unipersonal con la denominación de Dictador Supremo de la República, cargo para el cual fue elegido José Gaspar Rodríguez de Francia. En 1816 un nuevo Congreso General dispuso que Francia ejerciera el cargo de Dictador Perpetuo, gobernando por un período de 26 años hasta que falleció el 20 de septiembre de 1840, y otorgando la potestad al Dictador de convocar al Congreso cuando él lo considere necesario.

Tras un breve interregno entre 1840 y 1841 se conformó un segundo Consulado que estuvo integrado por Carlos Antonio López y Mariano Roque Alonso, quienes gobernaron por espacio de tres años entre 1841 y 1844. En dicho año Carlos Antonio López fue elegido Presidente de la República por el período 1844-1854, luego 1854- 
1857 y finalmente $1857-1867$, falleciendo en ejercicio del cargo el 10 de septiembre de 1862.

Como se ha señalado con anterioridad ya en el año 1813 los festejos para celebrar la Independencia habían disminuido, durante el prolongado gobierno de Francia no se registraron mayores festejos en dichas fechas según consta en la sección copias de las actas del cabildo de Asunción de dicho período. Pese a la leyenda que se esparció sobre el gobierno de Rodríguez de Francia, que sostenía que bajo su mando "la guitarra enmudeció" y por lo tanto no se realizaban fiestas públicas, hemos encontrado referencias de que las fiestas religiosas continuaron realizándose en aquellos años como las festividades de San Blas, que era el patrono de la ciudad, la Semana Santa y el de Corpus Christi según consta en las actas del cabildo de Asunción de los años 1822, 1823 y 1824 (Comisión Nacional del Bicentenario, 2009).

Al igual que dichas festividades religiosas también se conmemoraba el 6 de enero con motivo de la celebración del nacimiento del dictador José Gaspar Rodríguez de Francia, como en el caso de la Villa de Itapúa (hoy Encarnación) en 1837 informaba el subdelegado Casimiro Rojas "se han concluido las fiestas sin la menor novedad, practicadas en el día 6 del presente, hechas por los moradores y naturales del pueblo, y también hicieron de su parte los comerciantes brasileros todos los regocijos más decentes que pudieron, haciendo muchos con bastante lujo, habiéndose enarbolado este mismo día la bandera de la República, y hechas las salvas de cañón..." (Vázquez, 1975:320). Por su parte, el agente consular brasileño Manuel de Correa da Cámara, escribió el 29 de abril de 1829 cuanto sigue “... ignoro si por ocasión de estos días festivos hubo algún baile, o mejor fandango... como el que dio el delegado en el aniversario del Dictador, pero en lo que en cambio hubo tanta bebida, tanto juego..." (Vázquez, 1975: 281).

\section{b) Segunda etapa ( 1842-1870). De la ratificación de Independencia a los tiempos de Marte}

Tras el fallecimiento del dictador Rodríguez de Francia, el 20 de septiembre de 1840 , se sucedieron un total de cuatro gobiernos provisorios efímeros, hasta que el comandante general de armas, Mariano Roque Alonso, convocó al Congreso General que se reunió el 13 de mayo de 1841, en el cual se eligió al mencionado Mariano Roque Alonso y a Carlos Antonio López como cónsules de la República por un período de tres años.

El principal obstáculo para reestablecer el comercio y los vínculos con el Río de la Plata fue la oposición del director Juan Manuel de Rosas a reconocer la independencia del Paraguay, por considerarla una provincia que se había separado de la Confederación Argentina. Ante la iniciativa del ministro inglés Gordon, los cónsules convocaron a un Congreso General Extraordinario que se reunió el 25 de noviembre de 1842, en el cual se celebró la Ratificación Solemne de la Independencia Nacional, 
que sería jurada por todos los ciudadanos en todos los rincones de la República el 25 de diciembre del mismo año, antes de la misa mayor por el día de Navidad.

El hecho de que la jura de la Independencia Nacional se realizase en un día relevante para la liturgia cristiana, no sólo se explica que la mayor parte de la gente de la campaña llegaba a las poblaciones para participar de la misa, sino ante todo porque de esa forma se vinculaba la causa nacional a la celebración y conmemoración del nacimiento del Niño Dios de los cristianos, con el proceso de nacimiento y consolidación de la Independencia. De tal forma se asociaban ambos festejos, doce años después el periódico oficial del gobierno, publicó en diciembre de 1854 cuanto sigue:

"aprovechamos la oportunidad de anunciar a nuestros conciudadanos el fausto día 25 del corriente en que la Iglesia celebra el nacimiento de nuestro Señor Jesucristo, y la República el aniversario de la jura de su independencia, y soberanía nacional”. Continuaba el artículo haciendo mención a que "Quiera Dios dejarla crecer en paz y seguridad, llenarla de bendiciones y guardarla en el goce de la tranquilidad que ha disfrutado por más de cuatro décadas (El Semanario de Avisos y Conocimientos Útiles, 1854).

Cada diciembre El Semanario publicaba el acta de ratificación de la Independencia que debía ser leída en acto público en cada una de las poblaciones de la República. En 1858 además de dichas celebraciones en la capital se informaba que tres jóvenes estudiantes del aula de filosofía ${ }^{2}$ formularon arengas, los estudiantes que las hicieron fueron Natalicio Talavera, Mateo Collar y Juan de Rosa Franco.

El poeta guaireño Natalicio Talavera, se dirigió al público congregado en los siguientes términos:

\begin{abstract}
"Ilustres conciudadanos: Hay momentos felices en que elevándose el concepto humano por regiones pobladas de alagüeñas imágenes deja gravado [sic] en los corazones un anhelo inestinguible un empeño decisivo y grande y una voluntad pura que se despliega generosamente [...] a ese instante dicho hemos llegado, señores hoy celebramos con júbilo la jura de nuestra independencia; abramos nuestros corazones, sembremos en su fértil seno ese recuerdo glorioso que nos embriaga dulcemente...."(El Semanario de Avisos y Conocimientos Útiles, 1858).
\end{abstract}

\footnotetext{
${ }^{2}$ El aula de filosofía fue dirigida por el español Ildefonso Bermejo quien fue contratado por el gobierno paraguayo para organizar el sistema educativo paraguayo.
} 
Por su parte, Mateo Collar insistió en el patriotismo y los desvelos del presidente Carlos Antonio López sin nombrarlo para concluir su alocución con las siguientes palabras:

\begin{abstract}
"Ahora en memoria de la alegría y aplausos que derremasen[sic] nuestros corazones la solemnidad de este día y en recompensa de tantas gracias merecidas como fieles patriotas, pidamos á la providencia que corone nuestro júbilo [sic] con los dones esquisitos [sic] de la prosperidad infudiendo en nuestros pechos aquel fuego de amor patrio que sienten, los héroes cuando miran amenazada su independencia" ( $E l$ Semanario de Avisos y Conocimientos Útiles, 1858).
\end{abstract}

Además de los actos protocolares no se descuidaba el regocijo popular, por tal motivo se organizaron tres días de corridas de toros en honor a la Independencia Nacional y en la noche del 26 se realizó la representación de la comedia La Preciosa en dos actos y de la zarzuela La cola del Diablo (El Semanario de Avisos y Conocimientos Útiles, 1858).

Bajo el gobierno de Carlos Antonio López los festejos del 25 de diciembre cobraron mayor relevancia, pues incluso llegó a ser la conmemoración principal de la Independencia según se puede deducir de lo publicado el 24 de diciembre de 1859 “... mañana al despuntar el día el estampido del cañón recordara al pueblo paraguayo que la República cuenta con cuarenta y siete años de Independencia Nacional..." (El Semanario de Avisos y Conocimientos Útiles, 1859). Los festejos populares consistieron en tres días de carreras de sortijas. En 1861 la celebración del 25 de diciembre fue propicia para que se realice además el viaje inaugural del ferrocarril a la ciudad de Luque, por lo que se organizaron viajes gratuitos todo el día hasta esa población al igual que corridas de toros y carreras de sortija, tanto en Luque como en Trinidad ( $E l$ Semanario de Avisos y Conocimientos Útiles, 1861).

Tras el fallecimiento del presidente Carlos Antonio López el 10 de septiembre de 1862, le sucedió por un pliego reservado su hijo el general Francisco Solano López, quien a la sazón contaba con 35 años. El 27 de diciembre de 1862 El Semanario publicó un artículo como era costumbre en relación al recuerdo de la jura de la Independencia, y como se ha sostenido en dicho artículo se explicitó la importancia de dicha fecha, porque la misma estaba vinculada a la figura del entonces recientemente fallecido presidente cuando afirmaba:

"El jueves 25 del corriente se ha celebrado con la solemnidad de costumbre el aniversario de la jura de nuestra Independencia Nacional. Tan satisfactorio nos ha sido ver a nuestros compatriotas celebrar con júbilo y entusiasmo tan fausto día de la Nación. Honor al ilustre patriota D. Carlos 
Antonio Lopez, fundador de la nacionalidad paraguaya" (El Semanario de Avisos y Conocimientos Útiles, 1862).

De la crónica puede deducirse la consideración que se tenía sobre el rol de Carlos Antonio López en el proceso de la Independencia al contrastar con los festejos que se desarrollaron bajo su gobierno para conmemorar el 14 de mayo y el 12 de octubre.

Para recordar el aniversario de la Indepedencia en mayo de 1854 se manifestaba en el periódico oficial que:

"Tenemos el placer de recordar a nuestros conciudadanos que mañana celebramos uno de los días más grandes y memorables en los fastos del Paraguay, la revolución pacífica del 14 de mayo de 1811, que no ha costado una gota de sangre, una lágrima ni el menoscabo de intereses ningunos, prueba clara de que todos los ánimos estaban prevenidos por la Independencia" (El Semanario de Avisos y Conocimientos Útiles, 1854).

De los festejos participaron los altos funcionarios del estado y los miembros más representativos de la alta sociedad que fueron invitados a participar de un sarao en el salón del Congreso Nacional. Cuatro años más tarde en El Semanario se hacía la respectiva recordación al 14 de mayo, manifestando que el 14 de mayo “....señala el aniversario de la revolución del Paraguay que tuvo por objeto su separación del gobierno de las Provincias Unidas del Río de la Plata" (El Semanario de Avisos y Conocimientos Útiles, 1858).

Hacia fines de la década de 1850 , los festejos se fueron extendiendo al resto de la sociedad, según la crónica de 1859 en la noche del 13 la ciudad se iluminó y las bandas militares recorrieron la ciudad seguidas de un "gentio inmenso", además a lo largo del día 14 se escucharon salvas de artillería (El Semanario de Avisos y Conocimientos Útiles, 1859). Ese mismo tipo de celebraciones se realizaron para conmemorar la recordación de la proclamación de la Repúbica en octubre de 1860 (El Semanario de Avisos y Conocimientos Útiles, 1860).

Debido a la guerra civil en la República Oriental del Uruguay, y la posterior invasión de las tropas imperiales del Brasil a dicho país, el Paraguay remitió un ultimátum al emperador Pedro II, el 30 de agosto de 1864, cuando las tropas brasileñas invadieron el Uruguay el 7 de octubre de ese mismo año, el gobierno del Paraguay le declaró la guerra en noviembre de ese año.

En mayo de 1865 la recordación de la Revolución de Mayo de 1811, permitió al períodico oficial transmitir la idea que todo lo que es el Paraguay es gracias a su Independencia, cuando publicó "el suceso que conmemora el 14 de mayo nos ha abierto una nueva era, un manantial inagotable y fecundo para nuestra felicidad y si ponderamos 
nuestros progresos[...] no lo debemos sino a nuestra Independencia y a los medios que hemos adoptado para guiar de una manera moderada y tranquila los primeros pasos de nuestro país" (El Semanario de Avisos y Conocimientos Útiles, 1865).

Concluía el artículo invitando al pueblo a que actúe con un verdadero patriotismo, para actuar en forma uniforme contra las adversidades del momento.

El 10 de octubre de 1865 en su número 494, El Semanario hacia alusión a la conmemoración del 12 de octubre señalando que "el estampido del cañón nos hará recordar que saludamos el quincuagésimo primero aniversario del pronunciamiento de nuestra Independencia Nacional" (1865). Lo llamativa de la nota es que por primera vez en los diversos artículos se hace referencia a los "Padres de la Patria", pues ellos "... sellaron un hecho memorable, de donde emanan nuestra propia vida y nuestro rango de hijos de una nación libre é independiente" (El Semanario de Avisos y Conocimientos Útiles, 1865).

En el número 68 de Cabichui fechado el 26 de diciembre de 1867 se hizo un homenaje a la jura de la Independencia Paraguaya, a la cual se agregó un grabado que reproducía dicho acto realizado en 1842 . Al respecto de dicha conmemoración los redactores se refirieron a los actos de júbilo realizados en el propio frente de batalla, que por su riqueza, transcribimos a continuación:

"Al despuntar sobre nuestro horizonte los primeros rayos del sol, la magestatica detonación de los cañones de Humaitá, Espinillo y el Cuartel General saludaron el 25 DE DICIEMBRE.

Y desde ese momento todo nuestro campo resonó en estrepitosos ¡Vivas! Á la Patria libre e independiente, y á su ilustre Gefe el MARISCAL LOPEZ.

Las bandas de músicas, más armónicas y sónoras que nunca, quebraron los aires en toda la extensión de nuestras líneas.

La alegría y el entusiasmo se dibujaron gratamente en los marciales semblantes de los invictos defensores de la INDEPENDENCIA NACIONAL.

Todo Paso-Pucú se convirtió en una sublime horquesta [sic]: se encontró en los goces de una fiesta verdaderamente de todos y de trasunto celestial!

El campeón de la libertad, el héroe vencedor de un Imperio y dos Repúblicas, el esclarecido MARISCAL LÓPEZ [...] Eran las 12 del día cuando en el cuartel general hubo besamanos [...] el $\mathrm{S}^{\text {or }}$ obispo Palacios pronunció un espresivo discurso en que hacia resaltar los inmensos beneficios de que la Patria es deudora a su esclarecido Gefe, cuyo patriotismo y abnegación, su genio providencial [...] Después de esto tuvo lugar el acto de la presentación de una espada de honor 
por parte del pueblo paraguayo al Exmo Señor Mariscal Presidente en termino de su amor y gratitud..." (Cabichui, 1867).

De esta forma se puede apreciar que las fiestas de independencia conmemoradas en este período fueron 3: el 14 de mayo, el 12 de octubre y el 25 de diciembre, siendo esta última la más importante porque del acto conmemorado había participado el presidente Carlos Antonio López.

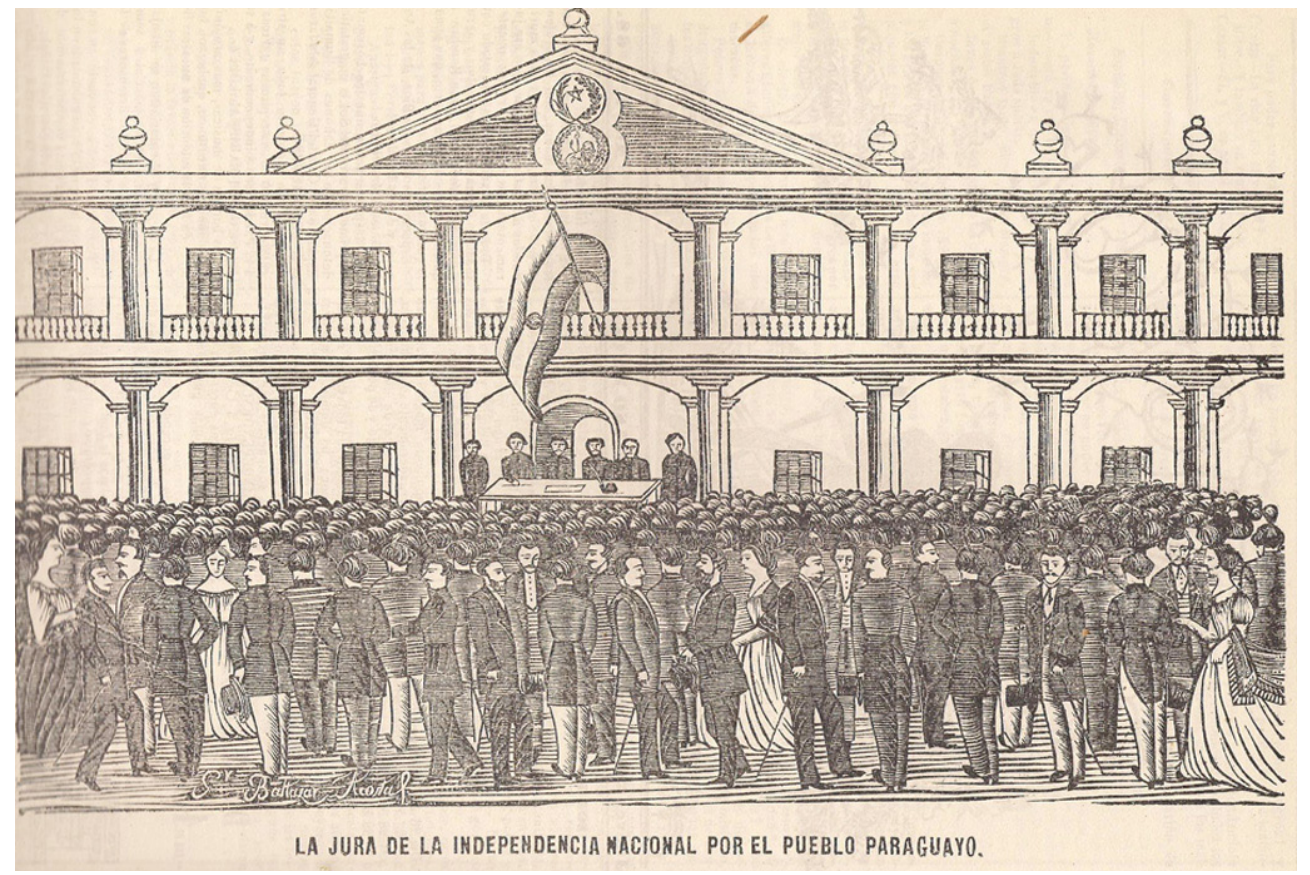

$1^{\circ}$ Grabado de El Cabichuí representando la jura de la independencia el 25 de diciembre de 1842

\section{c) La Etapa Liberal (1870-1900) De Fiesta de la Independencia a Fiestas Mayas}

La Guerra de la Triple Alianza (1864-1870) llegó a su final el 1 de marzo de 1870, en las estribaciones de la cordillera del Amambay, en la batalla de Cerro Corá, en la que fue destruido el último resto del ejército paraguayo comandado por el mariscal Francisco Solano López, quien también perdió la vida en dicha batalla. Pero pese a que López había trasladado la capital de la República primero Luque, luego a Piribebuy y posteriormente a Curuguaty, bajo el amparo de las tropas aliadas que ocuparon Asunción, funcionaba en dicha ciudad desde agosto de 1869 un gobierno provisorio ejercido por el Triunvirato integrado por Cirilo A. Rivarola, José Díaz de Bedoya y Carlos Loizaga. 
Como un hecho llamativo e indicador de los cambios que se sucedieron en el país, en el mes de mayo de 1870, los triunviros declararon feriado el 25 de mayo, en homenaje a la revolución de Independencia de la República Argentina (Registro Oficial, 1870). En el considerando del decreto se estableció "solo los intereses criminales y egoístas del dictador Francia y sus sucesores privaron al pueblo paraguayo de la participación en la grande lucha que dió por resultado la emancipación é independencia de las colonias americanas" (El Paraguay, 1870).

Otro aspecto significativo y de interés fue la utilización que se hará con respecto a los festejos de la independencia del Paraguay. Se denominará en adelante las FIESTAS MAYAS o de Mayo, nombre utilizado en los festejos de la independencia argentina. Juan Carlos Garavaglia afirma que dicho nombre fue establecido por la Asamblea el 5 de mayo de 1813 (2007:115).

Los festejos de la Independencia se centralizaron en el 14 de mayo, pero sin que fuera declarado feriado. En 1874, el periódico La Libertad recordaba en su edición del 13 de mayo lo siguiente: "Mañana es el gran día para la patria paraguaya, sus hijos deben regocijarse porqué de conquista en conquista van organizando una nación digna del pensamiento de independencia que animó a los primeros libertadores ( $\mathrm{La}$ Libertad, 1874). Al día siguiente los festejos consistieron en el TE DEUM, luego el pueblo disfruto de la parada de tropas, corrida de sortija y salvas de cañones y a la noche un gran baile, del cual participaron "todas las clases sociales". Lo llamativo es el reclamo a la indiferencia de los miembros del gobierno pues afirmaba dicho órgano de prensa que "ha sido notable la ausencia de algunos hombres públicos del Paraguay en el TE DEUM celebrado ayer en nuestra catedral, en acción de gracias por tan glorioso día. ¿Cómo el sentimiento patrio se va extinguiendo en los hijos de este suelo? ¿Se va acaso perdiendo el amor á esta patria que tanto cuesta? (La Libertad, 1874). Pero era evidente que los festejos no tenían los brillos de antes de la guerra, pues en 1875, los integrantes del gobierno encabezados por el propio presidente Juan Bautista Gill asistieron a sus respectivos despachos (La Patria, 1875).

En 1880, La Reforma publicó un relato sobre la Independencia Nacional, lo interesante del relato es la conclusión del mismo, pues es una visión que se irá instalando sobre quiénes realmente fueron los protagonistas de dicha gesta que debían ser considerados héroes, y por lo tanto quienes debían ser honrados cada 14 de mayo: "Gloria eterna á la memoria de los grandes ciudadanos de la patria Yegros, Caballero, Cabañas e Iturbe autores de la revolución paraguaya" (La Reforma, 1880). En dicho año se hizo una manifestación popular que partió de la plaza Constitución ante el pie de una pirámide construida para tal efecto. Los manifestantes precedidos de dos bandas militares fueron a la casa de las principales autoridades para saludarles por tan jubiloso día (La Reforma, 1880).

Pero luego los festejos de la Independencia no habían logrado consolidarse como una fiesta pública, la crónica periodística de 1882, hablaba "Ese memorable día que deberíamos festejar con toda esplendides [sic] y entusiasmo en medio de 
manifestaciones populares ha pasado casi desapercibido de parte del pueblo" (La Reforma, 1882).

Pero realmente vale la pena destacar que las celebraciones del año 1887 , traen una interesante novedad, que fue catalogada por el periódico El Imparcial como Patriótica Iniciativa. En el cabildo se reunió un grupo de ciudadanos que decidieron conformar una comisión que tenía como propósito erigir estatuas para recordar a los próceres, al respecto informaba el citado periódico que "Los pueblos tienen siempre el deber patriótico de venerar la memoria de aquellos de sus hijos que por sus heroicos esfuerzos y acrisoladas virtudes, deparándoles eternas pájinas [sic] de gloria cual sucede con los patricios Caballero, Yegros e Iturbe" (El Imparcial, 1887).

La Comisión estaba integrada por el presidente de la República Gral. Patricio Escobar como presidente honorario, como miembros honorarios los integrantes del gabinete ministerial, coronel Pedro Duarte, Agustín Cañete, Benjamin Aceval, Manuel Maciel y J.A. Meza.

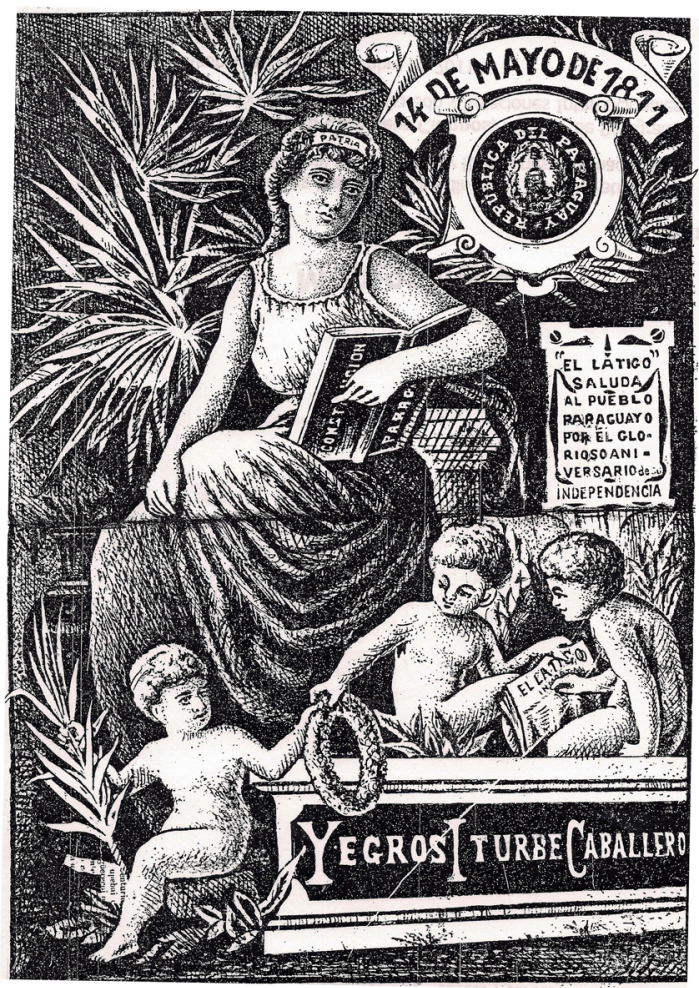

$2^{\circ}$ Grabado publicado en El Látigo Inmortal, en el que se aprecia la reivindicación a Yegros, Iturbe y Caballero

El presidente de la comisión era el general Bernardino Caballero, y los vocales de la misma, Cirilo Solalinde, José del Rosario Miranda, Juan de la Cruz Jiménez, José Segundo Decoud, Angel S. Martínez, coronel Juan Crisóstomo Centurión, José 
González Granado, doctor Zacarías Caminos, Francisco Guanes, Federico Muñoz, doctor Alejandro Audivert, Juan G. González, Rosendo Carisimo, Fernando Saguier y José Dolores Espinoza.(El Imparcial, 1887).

En 1892 para conmemorar un aniversario más de la Independencia, los jóvenes estudiantes del colegio Nacional, conformaron un batallón bautizado 14 de mayo que participó de los festejos acompañando a la infantería. Por otra parte los miembros de la Sociedad de Beneficencia prepararon una fiesta infantil en el Teatro Nacional, en beneficio de sus obras en el hospital de caridad. El programa fue muy nutrido, el festejo comenzó por canción Nacional, interpretada por 60 niños de ambos sexos, discurso de la niña Belén Fuster, la representación de la pieza La Casa de Campo, luego de la comedia Las Citas a Media Noche, y luego una comedia ¡Una idea feliz!, como conclusión de la mencionada actividad (La Democracia, 1892). La celebración inició la noche antes con una velada literaria musical organizada por el superintendente Manuel Amarilla, el 14 de mayo a partir de las 6 y media de la mañana los escolares se dirigieron a la plaza de Armas, y posteriormente lo hizo el batallón 14 de mayo organizado en tres compañías, con su uniforme "a la marinera". Se entonó el Himno Nacional, luego el presidente y los ministros y altos funcionarios salieron rumbo al Te Deum caminando en el medio del cordón formado por los escolares, para luego participar de la parada militar, en donde la sensación fue el batallón 14 de mayo, integrado por los estudiantes del Colegio Nacional. ( La Democracia, 1892). Al finalizar el acto los alumnos de las escuelas depositaron flores en la Pirámide de la Libertad dispuesta en la Plaza de Armas (El Independiente, 1892).

El 27 de septiembre de 1893, el senado aceptó el proyecto de ley para erigir un monumento a los próceres, los elegidos fueron Fulgencio Yegros, Pedro Juan Caballero y Manuel A Cabañas. La iniciativa de llevar adelante dicho monumento quedó a cargo de una sociedad de damas encabezada por la primera dama, la maestra Rosa Peña, quien organizó todo tipo de actividades para lograr su cometido. Al respecto señalaban las crónicas “ El P.E. dejó pasar el tiempo y nada se hizo. Pocos meses después há que algunas distinguidas señoras de la sociedad asuncena iniciaron un movimiento de opinión en el sentido de hacer práctica aquella sanción legislativa. Nadie se opuso. Callaron el congreso y el P.E. Y callaron igualmente la prensa y los ciudadanos. Las señoras comenzaron á arbitrar los fondos. Organizaron fiestas especiales, á cuyo éxito correspondieron la prensa y el pueblo nacional y extranjero [sic]" ( La Democracia, 1894).

Finalmente se decidió que la colocación de la piedra fundamental se haría el 14 de mayo de 1894. Para los festejos de ese año, el gobierno otorgó 5000 pesos fuertes a la comisión de ornato integrada por Ángel Peña, Juan B. Dávalos y Federico Fernández. Para el 5 de mayo se fijo el día de la licitación de la ornamentación de la ciudad. La municipalidad por su parte solicitó a los particulares y los comercios que adornen e iluminen sus predios en dichos días (La Democracia, 1894). Por su parte el superintendente Manuel Amarilla organizó el acto de colocación de la 
piedra fundamental, y asimismo dispuso la conformación de un batallón infantil que participaría de los actos de aniversario.

La colocación de la piedra fundmental generó una situación conflictiva, pues la comisión de damas invitó al acto a las sociedades masónicas, por lo que el clero manifestó que no bendeciría la piedra si los masones asistían con sus estandartes, motivo por el cual los integrantes de dicha sociedad secreta estuvieron presentes pero sin sus distintitivos. (El Pueblo, 1894). Tras la colocación de la piedra fundamental, hubo Te Deum en la Catedral, luego salvas de artillería y parada militar, en donde la participación de los batallones infantiles causo la nota distinta en dichos actos. Por la tarde se disputaron unas regatas en la bahía con la participación de mucho público y por la noche se desarrolló una actividad en el teatro (El Pueblo, 1894). La iniciativa no se concretó tal vez porque el presidente Juan G. González fue depuesto unos meses después y tuvo que marcharse al exilio junto con su esposa, la presidenta de la comisión de damas, doña Rosa Peña.

La celebración del año 1896, fue considerada por La Democracia, como "modestísima", la jornada comenzó con la reunión de los alumnos de las escuelas en la plaza Constitución, luego hubo Te Deum, y parada militar. Por la tarde hubo función escolar en la escuela Normal a la cual asistió el presidente Egusquiza. Tanto los edificios públicos como privados se iluminaron las noches del 13 y el 14. Las celebraciones concluyeron con una representación teatral. En Caazapá, se hizo entrega de premios a los estudiantes de la escuela Graduada de dicha población( La Democracia, 1896).

En 1897, el Instituto Paraguayo, a través de sus asociados organizó nuevamente una procesión cívica, a partir de las 3 de la tarde se desarrolló una tertulia literaria musical, en la cual dieron alocuciones Eusebio Ayala, Ignacio A. Pane y Alfredo S. Osorio, luego a las 5 de la tarde salió la procesión rumbo al palacio en donde iban a ser los encargados de las palabras de circunstancia Arsenio López Decoud y Manuel Domínguez. Para dicha procesión se contó con la presencia de las dos bandas militares de la ciudad (El Cívico, 1897).

El jueves 5 de mayo de 1898, El Cívico manifestaba que los festejos por la Independencia Nacional no podían limitarse al Te Deum, desfile de tropas y canto del Himno Nacional, instaba a la juventud a organizar procesiones civicas y tertulias literarias (El Cívico, 1898). El 14 de mayo se relizó una procesión cívica organizada por diversas asociaciones, la misma se congregó en la plaza Independencia, se dirigió al palacio de gobierno y luego recorrió la calle Palma hasta llegar a la plaza Uruguaya. El orden del desfile fue el siguiente:

" 5 año del Colegio Nacional, Universidad Nacional, Colegio Nacional, Instituto Paraguayo, Escuela Monseñor Lasagna, Sociedad Portuguesa de Socorros Mutuos, Sociedad Italiana de idem, Sociedad española idem, Sociedad Francesa idem, Sociedad Alemana Idem, Sociedad Eslava d' Socorros Mutuos, Sociedad Suiza d' idem, Sociedad Argentina de 
idem, Sociedad Tipográfica del Paraguay, Logia Aurora del Paraguay, idem universo núm. 1, idem Federico el Grande, idem Sol Naciente, idem Garibaldi, idem Libertad, idem Igualdad, Sociedad Veteranos de Guerra, y en seguida el pueblo" (El Cívico, 1898).

Al años siguiente se volvió a reunir una procesión cívica cuya organización estuvo encabezada por el Instituto Paraguayo, agrupación que nucleaba a los principales intelectuales y hombres de artes y literatura de la época.

\section{Consideraciones Finales}

Durante el gobierno de Carlos Antonio López, se desplegó toda la labor diplomática a favor de lograr el reconocimiento de la Independencia Nacional por parte de la Confederación Argentina. El gobierno desarrolló una política de celebraciones con el fin de divulgar entre el pueblo la relevancia de la Independencia Nacional, es así que se conmemoraba el 14 de mayo, el 12 de octubre y el 25 de diciembre, siendo está última fecha en la cual se desarrollaban los principales festejos.

Podemos señalar que la conmemoración desde un inicio tuvo por objetivo principal el recordar el origen de la República y era claro que los propios protagonistas de la Revolución de Mayo de 1811, eran conscientes de ello, por lo que se organizaron los festejos del año 1812, aún con una cierta mezcla de ceremonia real, pues se realizó el paseo del real estandarte. La ceremonia de celebración continúo enmarcada en las celebraciones propias del antiguo régimen, iluminación, besamanos y funciones populares.

El vínculo entre lo religioso y lo republicano se produjo con el fin de reforzar la idea de la Independencia, es así que la jura solemne de la Independencia se realizó el 25 de diciembre de 1842, a partir de dicha fecha son varias las celebraciones que se organizaron para conmemorar esa fecha vinculando en el discurso oficial el nacimiento de Jesucristo y de la jura de la ratificación de la Independencia. Dicha conmemoración también era aprovechada para destacar la figura del entonces presidente de la República Carlos Antonio López, quien había encabezado dicho acto, aunque en realidad lo hizo también el cónsul Mariano Roque Alonso, pero éste fue olvidado en todos los festejos y alusiones a tan importante fecha celebratoria.

La transformación más importante se produjo en la tercera etapa tras la finalización de la guerra contra la Triple Alianza. En dicho período hubo años como en 1875, en que el presidente siguió trabajando normalmente un 14 de mayo. Los actos se volvieron solemnes y repetitivos pero la iniciativa de la ciudadanía a través de diversas organizaciones que le fueron dando un matiz más inclusivo a la conmemoración de la Independencia Nacional hacia fines del siglo XIX. 
Folia Histórica del Nordeste, N$^{0} 21$ (Resistencia, 2013) IIGHI, IH - CONICET, UNNE

Por último, si bien el gobierno de acuerdo al contexto político de su época utilizó la recordación con un fin ideológico, y por sobre todo para enviar el mensaje de interpretación histórica sobre quiénes fueron los líderes de la independencia.

\section{Referencias bibliografícas}

Anderson, B. 2006. Comunidades Imaginadas. Reflexiones sobre el origen y la difusión del Nacionalismo. México. Fondo de Cultura Económica.

Arias, D. D. 2007. "Memoria Colectiva y Ceremonias Conmemorativas. Una aproximación teórica". Diálogos. Revista Electrónica de Historia , 170-191.

Aróstegui, J. 2001. La Investigación Histórica: Teoría y Método. España: Crítica.

Basile, M. O. 2006. "Festas civicas na Corte Regencial. Civic celebrations in the Rio de Janeiro Court during the regency period". Varia Historia , 494-516.

Braudel, F. 1991. Escritos sobre historia. México: Fondo de Cultura Económica.

Burke, P. 2000. Formas de Historia Cultural. Madrid: Alianza Editorial.

Carretero, M. 2007. Documentos de Identidad. La Construcción de la Memoria Histórica en un Mundo Global. Buenos Aires: Paidos SAICF.

Chiaramonte, J. C. 2004. Nación y Estado en Iberoamérica. El lenguaje político en tiempos de las independencias . Buenos Aires: Editorial Sudamericana.

Comisión Nacional del Bicentenario. 2009. Actas del Cabildo de la Asunción 1822-1824. Asunción: Servilibro.

Cruells, A. P. 2006. "Ciudad, Fiesta y Poder en el Mundo Contemporaneo". Liminar, Estudios Sociales y Humanísticos, 36-49.

Garavaglia, J. C. 2000. "A la Nación por la fiesta: Las Fiestas Mayas en el Origen de la Nación en el Plata". Boletín del Instituto de Historia Argentina y Americana " Dr. Emilio Ravignani", 73-100.

Garavaglia, J. C. 2010. “A la nación por la fiesta: las Fiestas Mayas en el origen de la nación en el Plata". Revista de Historia Bonaerense, 2-14.

Garavaglia, J. C. 2002. "Buenos Aires y Salta en rito cívico: La Revolución y las fiestas mayas". Andes, 1-26.

Garavaglia, J. C. 2007. Construir el estado, inventar la nación. Río de la Plata, siglos XVIII-XIX . Buenos Aires: Prometeo Libros.

Hobsbawn, E. 1998. Sobre la Historia. Barcelona: Crítica. y Ranger, E. H. 2002. La Invención de la Tradición. Barcelona : Crítica.

Maíz, F. 18 de mayo de 1896. "14 de mayo 1811-1896”. La Democracia, pág. 1.

Manuel Chust, V. M. 2003. La Construcción del héroe en España y méxico (1789-1847). Valencia : Publicaciones de la Universidad de Valencia .

Ortemberg, P. 2004. Algunas reflexiones sobre el derrotero social de la simbología republicana en tres casos latinoamericanos. La construcción de las nuevas identidades políticas en el siglo XIX y la Lucha por la legitimidad. Revista de Indias , 697-720.

Pane, J. A. 13 de mayo de 1898. "14 de mayo de 1811”. El Cívico , pág. 1.

Paraguay. Registro Oficial, Asunción 1870.

Pérez-Rayón, N. 1993. La sociología de lo cotidiano: Discursos y fiestas cívicas en el México de 1900: La Historia en la conformación de la identidad nacional. Sociológica. Recista del Departamento de Sociología .

Peters, H. 1996. El Sistema Educativo paraguayo desde 1811 hasta 1865. Asunción: Instituto Cultural Paraguayo-Alemán .

Prost, A. 2001. Doce Lecciones Sobre Historia . Madrid: Frónesis Cátedra Universitat de Valencia. 
Caballero Campos. Las celebraciones de la independencia del Paraguay.

Silva, A. M. 2010. La noche de las Kygua Vera. La Mujer y la reconstrucción de la identidad nacional en la posguerra de la Triple Alianza (1867-1904). Asunción: Intercontinental .

Smith, A. 2001. Nacionalismo. España: Alianza.

Subercaseaux, B. 2002. Nacióny Cultura en América Latina Diversidad Culturaly Globalización. Santiago: Escafandra.

Talavera, N. 13 de diciembre de 1858. “Arengas”. El Semanario de Avisos y Conocimientos Utiles, pág. 5.

Vázquez, J. A. 1975. El Doctor Francia Visto y Oído por sus contemporáneos. Buenos Aires : EUDEBA.

Viola, A. 2003. El Diario de Sucesos Memorables. Asunción: Academia Paraguaya de la Historia.

Whigham, T. 20 de marzo de 2006. La guerra destruye, la guerra construye. Ensayo sobre el desarrollo del nacionalismo en Sudamérica. Recuperado el 10 de 03 de 2012, de Nuevo Mundo, Mundos Nuevos : http://nuevomundo.revues.org/2074

\section{Periódicos Consultados}

El Artesano, Asunción, 1886.

El Cabichui, Asunción, 1867.

El Centinela, Asunción, 1867.

La Democracia, Asunción, 1889, 1890, 1892, 1894, 1896, 1899.

El Cívico, Asunción, 1897, 1898.

El Independiente, Asunción, 1892.

El Imparcial, Asunción, 1887.

El Heraldo, Asunción, 1885.

El Orden, Asunción, 1886.

El Látigo Inmortal, Asunción 1885

La Libertad, Asunción, 1874.

La Patria, Asunción, 1875.

El Paraguay, Asunción, 1870.

El Paraguayo, Asunción, 1888.

El Pueblo, Asunción, 1894, 1895.

La Reforma, Asunción, 1880, 1881, 1882, 1884.

El Semanario de Avisos y Conocimientos Útiles, Asunción, 1854, 1858, 1859, 1860,1861, 1862, 1865. 